\title{
Study of sensory processing deficits in autism spectrum disorder symptom triad: an Egyptian sample
}

\author{
Mona Reda', Nagwa A. Meguid ${ }^{2}$, Ola M. Eid ${ }^{3}$, Fatma Hussein² and Dina Y. Elalfy ${ }^{1 *}$ (D)
}

\begin{abstract}
Background: Autism spectrum disorder (ASD) is one of the most common neurodevelopmental disorders. In DSMIV, the diagnostic criteria of autism consisted of three domains: impairment in social interaction, communication deficits, and stereotypic behavior, while in DSM-5 they were condensed into two domains: social communication deficits and restricted patterns of behavior to which sensory processing deficits (SPD) were added, manifested by hypo- or hyper-reactivity to sensory stimuli or uncommon interests in sensory aspects of the surrounding environment. The purpose of this study is to determine the relation between SPD and the symptom triad in ASD namely social interaction, communication deficits, and stereotypic behavior. To our knowledge, this issue was not studied before in Egyptian literature.
\end{abstract}

Results: There was a significant negative correlation between SPD (assessed by short sensory profile: SSP) and symptom triad in ASD. As regards social interaction, the ADI-R (A), there was significant negative correlation with the SSP total scores and all subscales except for low energy/weak and visual/auditory sensitivity, whereas underresponsive/seeks sensation held the highest negative correlation $(p<0.008)$. As regards communication deficits, the ADI-R (B), there was significant negative correlation with the SSP total scores and the auditory filtering held the highest negative correlation ( $p<0.008$ ), and as regards stereotypic behavior, the ADI-R (C), there was significant negative correlation with the SSP total scores and all subscales except for low energy/weak and visual/auditory sensitivity whereas taste/smell sensitivity and auditory filtering held the highest negative correlation $\left(p^{<} 0.001\right)$. There was a high significant negative correlation between the severity of autistic symptoms (assessed by CARS) and the SSP total scores, and for all subscales ( $p$ < 0.001) except for low energy/weak, the correlation was significant (not highly significant) ( $\left.p^{<} 0.05\right)$. Finally, there was high percentage of parental consanguinity among the participants (80\%).

Conclusions: SPD negatively affected the ASD symptom triad which highlights the importance of sensory integration therapy (SIT) as a major core of ASD treatment alongside the other treatment modalities. Early ASD screening is mandatory in families with parental consanguinity.

Keywords: Autism spectrum disorder, Sensory processing deficits, Short sensory profile

\footnotetext{
* Correspondence: denaelalfy@yahoo.com

'Department of Medical Studies for Children, Faculty of Postgraduate

Childhood Studies, Ain Shams University, Cairo, Egypt

Full list of author information is available at the end of the article
}

\section{Springer Open}

(c) The Author(s). 2021 Open Access This article is licensed under a Creative Commons Attribution 4.0 International License, which permits use, sharing, adaptation, distribution and reproduction in any medium or format, as long as you give appropriate credit to the original author(s) and the source, provide a link to the Creative Commons licence, and indicate if changes were made. The images or other third party material in this article are included in the article's Creative Commons licence, unless indicated otherwise in a credit line to the material. If material is not included in the article's Creative Commons licence and your intended use is not permitted by statutory regulation or exceeds the permitted use, you will need to obtain permission directly from the copyright holder. To view a copy of this licence, visit http://creativecommons.org/licenses/by/4.0/. 


\section{Background}

Autism spectrum disorder (ASD) is one of the most common neurodevelopmental disorders. Worldwide prevalence is $1-2 \%$ of the population with an average male to female ratio of 4-5:1 [1].

The prevalence of ASD among the developmentally disabled children in Egypt was estimated to be 33.6\% [2].

Meanwhile, in the USA, prevalence of ASD (among children aged 8 years) has increased from one in 150 children during 2000-2002 to one in 68 during 20102012, reaching 1 in 59 children in the 2014 survey [3].

This increase is hypothesized partly due to changes in the understanding of the disorder and diagnostic methods, and partly due to an actual increase in ASD [4].

Sensory hypo-responsiveness or hyper-responsiveness was considered in DSM-III as infantile autism-associated features [5], while DSM-III-R and DSM-IV did not include sensory abnormalities as definite diagnostic criteria [6, 7].

In DSM-IV, the diagnostic criteria of autism was a triad of symptoms: social interaction impairment, communication deficits, and stereotypic behavior, while in DSM-5 they were condensed into two domains: the deficits in social communication and restricted patterns of behavior which included an added behavior of hyper- or hypo-reactivity to sensory stimuli or unusual attentiveness in sensory aspects of the environment [1].

Sensory processing deficits (SPD) in ASD were reported across all ages and levels of symptom severity. They adversely affect daily functioning and academic performance [8].

In autistic children, sensory abnormalities are from the earliest symptoms emerging in infancy as early as 6 months of age [9].

The following are some of the examples of sensory abnormalities cited by the DSM-5: visual fascination with lights or spinning objects; adverse response to specific sounds or textures; excessive smelling or touching of objects; apparent indifference to pain, heat, or cold. Almost any sensory channel may be involved, either in the sense of reduced responsiveness to stimulation or in the sense of excessive responsiveness to stimulation. There may be several types of sensory abnormalities in the same person throughout life, or even at the same time [10].

To our knowledge, the relation between SPD and other symptoms in ASD was not studied among Egyptian children. Moreover, the sensory integration therapy designed to improve SPD is rarely used in ASD children in Egypt unlike the other modalities of therapy.

The present study aimed to assess the relation between SPD and symptom triad in ASD.

\section{Methods}

This descriptive, cross-sectional study was conducted on forty children (27 males and 13females) diagnosed with
ASD according to the diagnostic criteria in DSM-5 [10]. The participants were attending the Autism Disorders Clinic, Medical Research Centre of Excellence, National Research Centre, Cairo, Egypt. The participants were collected during the period from October 2017 to February 2018.

\section{Inclusion criteria of the participants}

Children diagnosed with ASD, using DSM-5 [10] and Autism Diagnostic Interview-Revised (ADI-R) [11], with age ranged between 2 and 5 years were included.

\section{Exclusion criteria of the participants}

Cases with congenital syndromes, neurological and metabolic disorders (to limit confounding comorbidity) were excluded.

All participants were subjected to the following:

1. Full history taking including demographic data

2. Clinical examination

a. General examination to detect any systemic illnesses in the heart, chest, or abdomen

b. Neurological examination

3. Confirmed diagnosis according to the criteria of DSM-5 and ADI-R

4. Assessment of SPD using short sensory profile (SSP)

5. Assessment of the severity of autistic symptoms using Childhood Autism Rating Scale (CARS)

\section{ADI-R}

ADI- $R$ is a semi-structured standardized, investigatorbased interview for caregivers using the ICD-10 and DSM-IV-TR guidelines for autism. It can be used for diagnostic purposes and treatment planning for any child with a mental age of at least 18 months and focuses on abnormalities in three main domains; reciprocal social interaction (A), communication and language (B), and restricted, repetitive, and stereotyped behaviors $(C)$ [11].

\section{SSP}

$\mathrm{SSP}$ is a 38-item questionnaire intended to rate a variety of sensory impairments. Domain scores were measured in the areas of tactile sensitivity, taste/smell sensitivity, movement sensitivity, seeking sensation, auditory filtering, low energy levels, and visual/auditory sensitivity. Domain scores and overall sensory responses were categorized as typical performance, probable difference from typical performance, or definite difference from typical performance. The SSP assists occupational therapists in assessing and planning much-needed interventions for children with ASD such as sensory integration therapy [12]. 


\section{CARS}

CARS is a 15-item behavior rating scale which helps to identify and classify children with autism. Each item is scored from one to four as no, mild, moderate, and severe. Severe gets a score of 4 . Scores are added and the following scale is used: non-autistic scored 15-29, mildly-moderately autistic scored 30-37, and severely autistic scored 37-60 [13].

\section{Statistical analysis}

Recorded data were analyzed using the Statistical Package for Social Sciences, version 20.0 (SPSS Inc., Chicago, Illinois, USA). Quantitative data were expressed as mean \pm standard deviation (SD). Qualitative data were expressed as frequency and percentage.

\section{Results}

Application of ADI-R on the participants revealed the following: As regards reciprocal social interaction (A), the range [mean $\pm \mathrm{SD}]$ was $10-26[16.975 \pm 4.15]$ and the cutoff score is 10 . As regards communication abnormalities (B), $10 \%$ of the participants had verbal abnormalities (V) while 90\% had non-verbal abnormalities $(\mathrm{NV})$ with a range [mean $\pm \mathrm{SD}]$ of $6-14[10.65 \pm 2.27]$, and the cutoff score is 8 (if verbal) or 7 (if non-verbal). As regards restricted, repetitive, and stereotyped patterns of behavior $(\mathrm{C})$, the range $[$ mean $\pm \mathrm{SD}]$ was $3-12[6.7 \pm$ 2.4 ] and the cutoff score is 3. SSP application on the participants revealed the highest definite differences from normal in under-responsive/seeks sensation $(n=23$, $57.5 \%)$, followed by tactile sensitivity $(n=21,52.5 \%)$, auditory filtering $(n=20,50.0 \%)$, taste/smell sensitivity $(n=19,47.5 \%)$, visual/auditory sensitivity $(n=17$, $42.5 \%)$, and movement sensitivity ( $n=15,37.5 \%)$, while hypo-activity (low energy/weak domain) showed the lowest difference from normal $(n=14,35.0 \%)$.

In the SSP, a definite difference indicates scores greater than 2 standard deviations in the standardization sample, whereas a probable difference indicates scores greater than 1 and less than 2 standard deviations from children who were normally developing. Here, $77.5 \%$ of cases $(n=31$ out of 40$)$ fell into the category of probable and definite differences from what is seen in normally developing children on the SSP overall score. (Table 1)

Assessment of the relation between the ADI-R reciprocal social interaction domain (A) and SSP revealed a negative correlation with the SSP total and all subscales scores except for low energy/weak domain whereas under-responsive/seeks sensation held the highest negative correlation $\left(p^{<}\right.$0.008). This means that participants with more sensory symptoms showed more impairment in social interaction (Table 2 and Fig. 1).

There was a negative correlation between the ADI-R communication abnormalities (B) and the SSP total and all subscales scores except for movement sensitivity, low energy/weak, and visual/ auditory sensitivity domains and the auditory filtering held the highest negative correlation $\left(p^{<} 0.008\right)$. This means that participants with more sensory symptoms showed more impairment in communication (Table 3 and Fig. 2).

On assessing the relation between the ADI-R restricted, repetitive, and stereotyped patterns of behavior $(\mathrm{C})$ and SSP, there was a negative correlation with the SSP total and all subscales scores except for low energy/weak and visual/auditory sensitivity whereas taste/smell sensitivity and auditory filtering held the highest negative correlation $\left(p^{<} 0.001\right)$. This means that participants with more sensory symptoms showed more restricted, repetitive, and stereotyped patterns of behavior (Table 4 and Fig. 3).

There was a high significant negative correlation between the severity of autistic symptoms (assessed by CARS) and the SSP total scores and all subscales ( $p$ 0.001) except for low energy/weak; the correlation was significant (not highly significant) $(p<0.05)$. In other words, the severely autistic the child was, the more sensory deficits he/she suffered (Table 5 and Fig. 4).

Lastly, we found high percentage of parental consanguinity among the participants (80\%). Of them, 37.5\% were mildly autistic, $15 \%$ were moderately autistic, and $47.5 \%$ were severely autistic.

Table 1 SSP subscales and overall total scores of the participants

\begin{tabular}{llll}
\hline SSP \\
$\mathbf{n}=\mathbf{4 0}$ & Normal & Probable difference & Definite difference \\
\hline Tactile sensitivity & $11(27.5 \%)$ & $8(20.0 \%)$ & $21(52.5 \%)$ \\
Taste/smell sensitivity & $7(17.5 \%)$ & $14(35.0 \%)$ & $19(47.5 \%)$ \\
Movement sensitivity & $11(27.5 \%)$ & $14(35.0 \%)$ & $15(37.5 \%)$ \\
Under-responsive/seeks sensation & $9(22.5 \%)$ & $8(20.0 \%)$ & $23(57.5 \%)$ \\
Auditory filtering & $10(25.0 \%)$ & $10(25.0 \%)$ & $20(50.0 \%)$ \\
Low energy/weak & $18(45.0 \%)$ & $8(20.0 \%)$ & $14(35.0 \%)$ \\
Visual/auditory sensitivity & $8(20.0 \%)$ & $15(37.5 \%)$ & $17(42.5 \%)$ \\
Total SSP & $9(22.5 \%)$ & $5(12.5 \%)$ & $26(65.0 \%)$ \\
\hline
\end{tabular}


Table 2 Correlation between ADI-R (A) and SSP of the participants

\begin{tabular}{lll}
\hline SSP & \multicolumn{2}{l}{$\mathbf{A}$ (reciprocal social interaction) } \\
\cline { 2 - 3 } & $\boldsymbol{R}$ & $\boldsymbol{p}$ value \\
\hline Tactile sensitivity & $-.520^{* *}$ & $<0.001^{* *}$ \\
Taste/smell sensitivity & $-.404^{* *}$ & $0.010^{*}$ \\
Movement sensitivity & $-.443^{* *}$ & $0.004^{*}$ \\
Under-responsive/seeks sensation & $-.412^{* *}$ & $0.008^{*}$ \\
Auditory filtering & $-.386^{*}$ & $0.014^{*}$ \\
Low energy/ weak & -0.054 & 0.742 \\
Visual/auditory sensitivity & -0.298 & 0.062 \\
Total SSP & $-.470^{* *}$ & $0.002^{*}$ \\
\hline
\end{tabular}

$r$ Pearson correlation coefficient

${ }^{*} p$ value $<0.05 \mathrm{~S}$; ${ }^{* *} p$ value $<0.001 \mathrm{HS}$

\section{Discussion}

SPD has been added to the diagnostic criteria of ASD in DSM-5 in 2013, but the relation between SPD and the other diagnostic criteria of ASD was not in focus in Egyptian literature.

SPD may be considered central in autistic symptomatology as it precedes and predicts the occurrence of social interaction impairment and repetitive behaviors in the developmental cascade [14].

Although the presence of SPD may pass unnoticed, if it is not treated it reduces the response to treatment of other symptoms in ASD [15].

In our study, the most affected sensory processing was in under-responsive/seeks sensation (57.5\%), followed by tactile sensitivity (52.5\%), auditory filtering (50.0\%), taste/ smell sensitivity (47.5\%), and visual/ auditory sensitivity (42.5\%), while the least affected sensory
Table 3 Correlation between ADI-R (B) and SSP of the participants

\begin{tabular}{lll}
\hline SSP & \multicolumn{2}{l}{$\mathbf{B}$ (communication) } \\
\cline { 2 - 3 } & $\boldsymbol{R}$ & $\boldsymbol{p}$ value \\
\hline Tactile sensitivity & $-.419^{* *}$ & $0.007^{*}$ \\
Taste/smell sensitivity & $-.422^{* *}$ & $0.007^{*}$ \\
Movement sensitivity & -0.263 & 0.101 \\
Under-responsive/seeks sensation & -0.284 & 0.076 \\
Auditory filtering & $-.413^{* *}$ & $0.008^{*}$ \\
Low energy/weak & -0.150 & 0.356 \\
Visual/auditory sensitivity & -0.240 & 0.136 \\
Total SSP & $-.416^{* *}$ & $0.008^{*}$ \\
\hline
\end{tabular}

$r$ Pearson correlation coefficient

${ }^{*} p$ value $<0.05 \mathrm{~S} ;{ }^{* *} p$ value $<0.001 \mathrm{HS}$

processing was hypo-activity (low energy/ weak subscale) (35.0\%).

Our results were consistent with a study by Kojovic et al. [14] who found sensory processing abnormalities in items of under-responsiveness/sensation seeking, auditory filtering, and tactile sensitivity sections in autistic children.

In agreement with the present study, came a study by Posar and Visconti [15] who found three main sensory patterns in children with ASD namely hyporesponsiveness, hyper-responsiveness, and sensory seeking.

Under-responsiveness/seeks sensation may reflect response to multiple sensory stimuli. Our participants seemed to seek sensory input from multiple sensory systems (e.g., auditory, vestibular, tactile, proprioception). Tasks involving multisensory input include difficulty

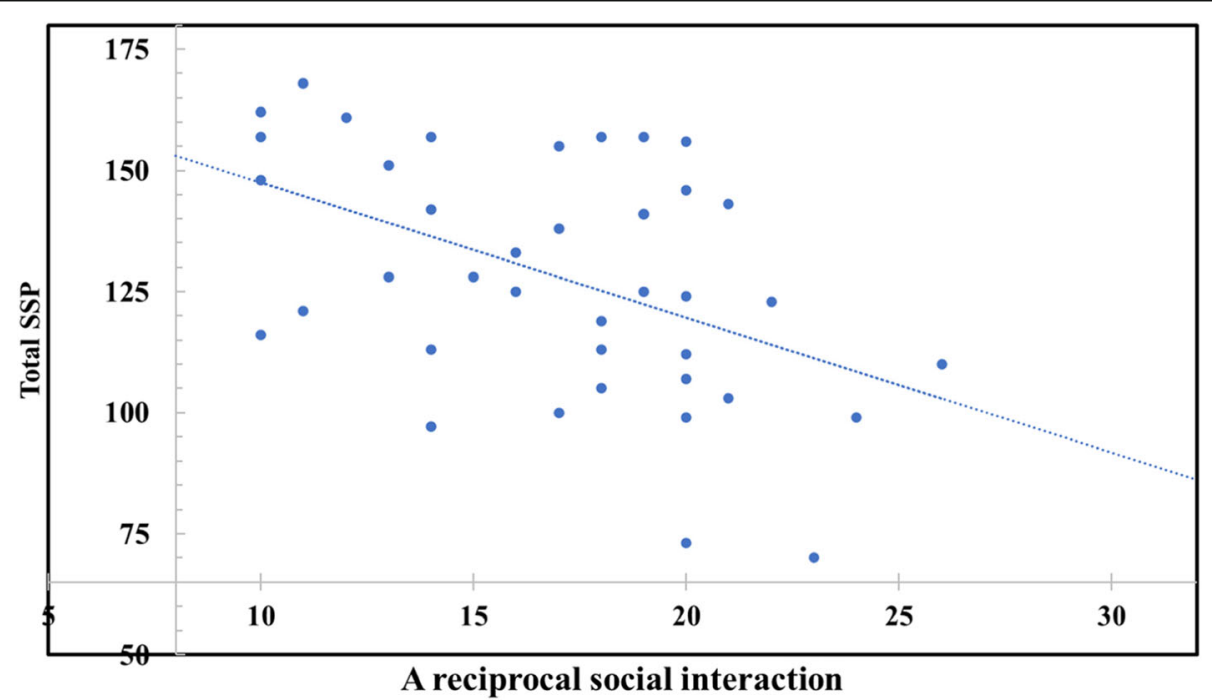

Fig. 1 Pearson correlation test between ADI-R (A) and total SSP. One-sided paired t-test analysis for the Pearson correlation test, $p<0.05$ 


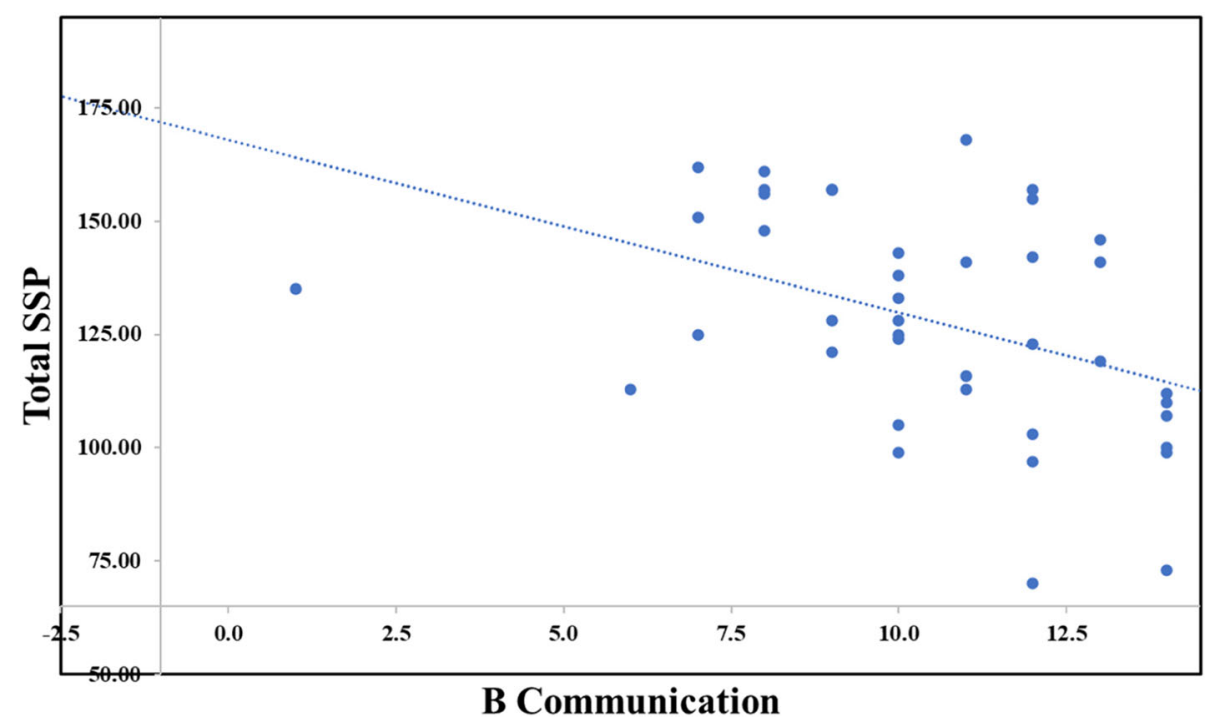

Fig. 2 Pearson correlation test between ADI-R (B) and total SSP. One-sided paired $t$-test analysis for the Pearson correlation test, $p<0.05$

paying attention, getting lost easily, fidgeting in an active environment, or leaving clothing twisted on the body.

Proper working of the multisensory system is mandatory for the integration of stimuli obtained from different sensory systems to perceive the environment accurately [16]. Several studies revealed multisensory abnormalities in autistic children [17-19].

As regards tactile sensitivity subscale, our participants seemed to be hyper-responsive to tactile stimuli in some items such as reacting emotionally or aggressively to touch, irritated when wearing shoes or socks, or avoiding being barefoot. While they were hyporesponsive in other items such as decreased awareness to pain and temperature, and not noticing when face or hands are messy.

Both hyper- and hypo-responsiveness to tactile stimuli are reported in autistic children [20-22]. and were steered together as the strongest predictors of social interaction deficits [23].
In contrast to under-responsiveness/seeks sensation and tactile sensitivity subscales which were among the highest definite difference from normal among our study participants, came the hypo-activity (low energy/ weak) subscale as the lowest in difference from normal. Most of the participants' parents reported that their children were strong, were active, had good tolerance, and were exploring their environment without a purpose.

This came in disagreement with various studies which found that this subscale is often seen in autistic children manifested by difficulty with sustained engagement in daily routines. The low energy/ weak domain includes items such as the following: seems to have weak muscles, poor tolerance/ tires easily, especially when standing or holding particular positions and props to support self [24].

In the present study, there was a negative correlation between the ADI-R reciprocal social interaction domain (A) and SSP (the SSP total and all subscales scores

Table 4 Correlation between ADI-R (C) of participants and SSP

\begin{tabular}{lll}
\hline SSP & \multicolumn{1}{c}{ (restricted, repetitive, and stereotyped patterns of behavior) } \\
\cline { 2 - 3 } & $\boldsymbol{R}$ & $\boldsymbol{p}$ value \\
\hline Tactile sensitivity & $-.368^{*}$ & $0.019^{*}$ \\
Taste/smell sensitivity & $-.568^{* *}$ & $<0.001^{* *}$ \\
Movement sensitivity & $-.401^{*}$ & $0.010^{*}$ \\
Under-responsive/seeks sensation & $-.432^{* *}$ & $0.005^{*}$ \\
Auditory filtering & $-.519^{* *}$ & $<0.001^{* *}$ \\
Low energy/weak & -0.099 & 0.545 \\
Visual/auditory sensitivity & -0.176 & 0.278 \\
Total SSP & $-.470^{* *}$ & $0.002^{*}$ \\
\hline
\end{tabular}

$r$ Pearson correlation coefficient

${ }^{*} p$ value $<0.05 \mathrm{~S} ;{ }^{* *} p$ value $<0.001 \mathrm{HS}$ 


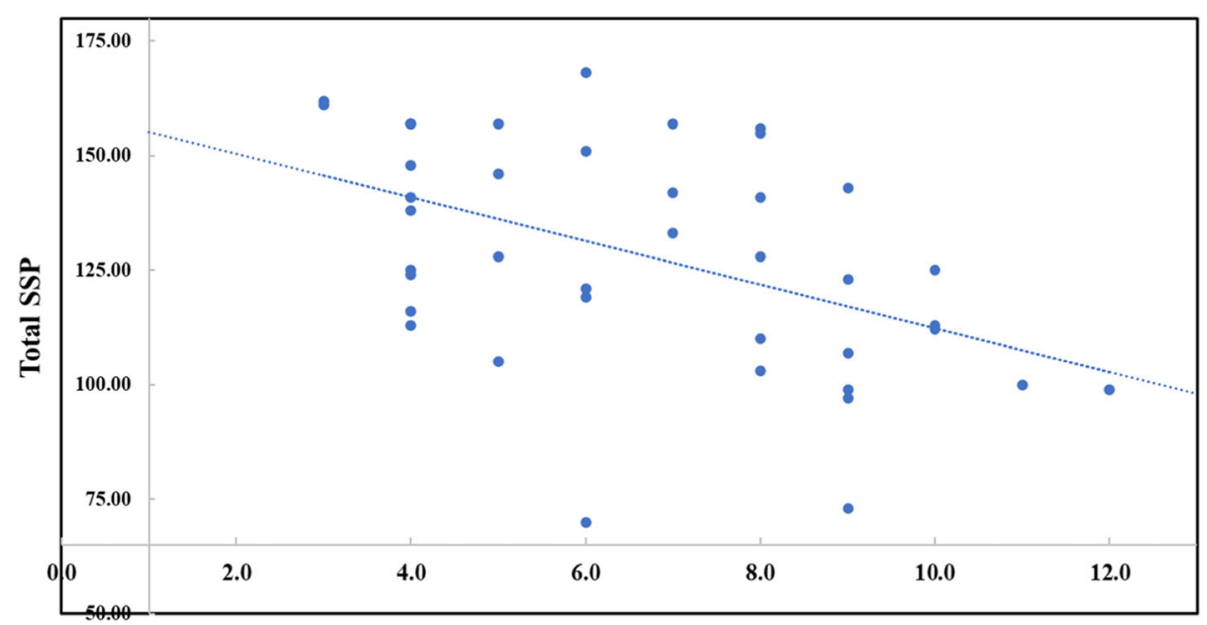

$C$ restricted, repetitive and stereotyped patterns behaviour

Fig. 3 Pearson Correlation test between ADI-R (C) and total SSP. One-sided paired $t$-test analysis for the Pearson correlation test, $p<0.05$

except for low energy/weak domain). This means that participants with more sensory symptoms showed more impairment in social interaction.

Thye and colleagues [18] revealed that primary sensory processing deficits in visual, auditory, tactile, and olfaction/gustatory responses could lead to social difficulties in ASD.

Also, our results came in agreement with a study done by Kojovic et al. [14] who confirmed the association between sensory processing and social impairments and its presence at a younger age before 6 years old.

We found a negative correlation relation between the ADI-R communication abnormalities (B) and the SSP total and all subscales scores except for movement sensitivity, low energy/weak, and visual/ auditory sensitivity domains. This means that participants with more sensory symptoms showed more impairment in communication.

Table 5 Correlation between CARS and SSP among the participants

\begin{tabular}{lll}
\hline SSP & CARS & \\
\cline { 2 - 3 } & $\boldsymbol{r}$ & $\boldsymbol{p}$ value \\
\hline Tactile sensitivity & $-.755^{* *}$ & $<0.001^{* *}$ \\
Taste/smell sensitivity & $-.818^{* *}$ & $<0.001^{* *}$ \\
Movement sensitivity & $-.605^{* *}$ & $<0.001^{* *}$ \\
Under-responsive/seeks sensation & $-.726^{* *}$ & $<0.001^{* *}$ \\
Auditory filtering & $-.693^{* *}$ & $<0.001^{* *}$ \\
Low energy/weak & $-.315^{*}$ & $0.048^{*}$ \\
Visual/auditory sensitivity & $-.556^{* *}$ & $<0.001^{* *}$ \\
Total SSP & $-.839^{* *}$ & $<0.001^{* *}$ \\
\hline
\end{tabular}

$r$ Pearson correlation coefficient

${ }^{*} p$ value $<0.05 \mathrm{~S} ;{ }^{* *} p$ value $<0.001 \mathrm{HS}$
Caminha and Lampreia [25] agreed with us as they related that sensory deficits were reflected in language and communication developmental deficits.

Studies revealed that SPD may have an effect on the essential sensorimotor skills concerned in nonverbal language and communication like gesture and imitation, therefore resulting in what is perceived as idiosyncratic behaviors, i.e., eye gaze aversion, limited non-verbal communication, and restricted facial expression. These atypical behaviors may later affect social learning opportunities, with a huge impact on development of effective social communication skills [26].

The present study revealed a negative correlation between the ADI-R restricted, repetitive, and stereotyped patterns of behavior $(C)$ and the SSP total and all subscale scores except for low energy/weak and visual/auditory sensitivity in our study. This means that participants with more sensory symptoms showed more restricted, repetitive, and stereotyped patterns of behavior.

Restricted and repetitive behaviors (RRBs) are core symptoms of ASD. Analytical studies applying ADI-R showed a pair of subclasses: repetitive motor and sensory behaviors like repetitive hand or finger movements, and insistence on sameness, together with limited interests, rigid routines, and rituals [27]. These classes of behaviors are usually correlative and frequently occur along within the same individual [28].

Previous studies discovered that SPD is often related to RRBs, where SPD were more obvious in people experiencing more RRBs [27, 29].

Indeed, sensory hypersensitivity could clarify the cooccurrence of anxiety and RRBs in ASD. RRBs may act 




Fig. 4 Pearson correlation test between CARS and total SSP. One-sided paired t-test analysis for the Pearson correlation test, $p<0.05$

as a coping mechanism to reduce anxiety resulting from sensory hypersensitivity [30].

In a study by Gal et al. [31], they found that stereotyped movements are initiated or terminated in response to sensory stimulation.

RRBs appear to reflect trials to control a chaotic perceived environment caused by sensory deficits in children with autism [25].

Better understanding of the effect of sensory profiles on adaptive behavior and therefore the development of behavioral issues in children with ASD should urge creating higher tailored clinical support [32].

Collectively, our study found a negative correlation between SPD and the symptom triad in autistic children.

Tavassoli et al. [33] agreed with our results as they suggested a negative correlation between SPD and other autistic symptoms.

Caminha and Lampreia [25] said sensory problems would promote the triad of impairment in autistic children from a developmental perspective.

In our study, children with more severe autism had more sensory deficits. CARS was negatively correlated with the SSP total and all subscales scores. These findings are consistent with several previous studies in which the severity of ASD had been associated with the severity of sensory deficits [34-37].

However, other studies found no significant difference between low and high functioning autism subgroups in the frequency of sensory symptoms [38].

In the present study, there was a high percentage of parental consanguinity ( $80 \%$ of the participants), $37.5 \%$ of them were mildly autistic, $15 \%$ were moderately autistic, and $47.5 \%$ were severely autistic, suggesting that parental consanguinity is a risk factor for ASD and predicts its severity. This highlights the importance of early screening of ASD in families with parental consanguinity.
The nearest percentage of paternal consanguinity in families with autistic children to our study was in a study conducted in Qatar who found paternal consanguinity in $45 \%$ of their studied sample and linked it to the ASD severity [39].

In another Egyptian study, there was parental consanguinity in $20 \%$ of the forty studied autistic cases [40].

Meanwhile in Israel, there was a significant difference regarding parental consanguinity in families of autistic children between Arabs (21.1\%) and Jews (2.3\%) [41].

And in the first epidemiological Iranian study of autistic children, the paternal consanguinity was $32.4 \%$ [42].

The high percentage of parental consanguinity in our results may be due to small sample size or such a coincidence as the participants were selected randomly from the autistic children attending the ASD clinic. This issue needs further studies.

\section{Conclusion}

SPD negatively affects symptom triad in ASD namely social interaction, communication deficits, and stereotypic behavior which highlights the importance of sensory integration therapy (SIT) (which is unfortunately rarely used in Egypt) as a major core in ASD therapy alongside the other treatment modalities and therefore we recommend the implementation of SIT in facilities concerned with ASD treatment all over Egypt if possible. Parental consanguinity may be considered a risk factor for ASD and predicts its severity so early screening of ASD in families with parental consanguinity is mandatory.

\section{Abbreviations}

ADI-R: Autism Diagnostic Interview-Revised; ASD: Autism spectrum disorder: CARS: Childhood Autism Rating Scale; DSM-III: Diagnostic and Statistical Manual of Mental Disorders-Third Edition; DSM-IV: Diagnostic and Statistical Manual of Mental Disorders-Fourth Edition; DSM-IV-TR: Diagnostic and Statistical Manual of Mental Disorders-Fourth Edition Revised; DSM5: Diagnostic and Statistical Manual of Mental Disorders-Fifth Edition; ICD10: International Classification of Diseases $10^{\text {th }}$ Revision; RRBs: Restricted and 
repetitive behaviors; SIT: Sensory integration therapy; SPD: Sensory processing deficits; SSP: Short sensory profile

\section{Acknowledgements}

We would like to acknowledge and thank all participants and their families in the current study for their valuable time.

\section{Authors' contributions}

MR contributed to the study concept and design and revision of the manuscript. NM contributed to the study concept and design and revision of the manuscript. OE contributed to the study design. FH recruited and studied the patients, gathered all data, and formed the results. DE contributed to the study concept and design, analysis and interpretation of results, and writing and editing the manuscript. All authors have read and approved the manuscript.

\section{Funding}

We did not receive any funding for this research.

\section{Availability of data and materials}

Not available

\section{Ethics approval and consent to participate}

Ethical consideration and approval according to the instruction of the research ethics committee in the Institute of Postgraduate Childhood studies (IPGCS, 2014) and National Research Center were taken in accordance to the code of ethics of the World Medical Association (Declaration of Helsinki, 1989) for experiments involving humans.

A written informed consent was obtained from the parents after explanation of the aim of the study and its benefits for their children and an oral consent was taken from the child.

\section{Consent for publication}

All authors agreed to publish this manuscript in the journal after reviewing the final version.

\section{Competing interests}

The authors declare that they have no competing interests.

\section{Author details}

${ }^{1}$ Department of Medical Studies for Children, Faculty of Postgraduate Childhood Studies, Ain Shams University, Cairo, Egypt. ²Department of Research on Children with Special Needs, National Research Centre, Cairo, Egypt. ${ }^{3}$ Department of Human Cytogenetics, National Research Centre, Cairo, Egypt.

Received: 30 September 2020 Accepted: 22 December 2020

Published online: 05 January 2021

\section{References}

1. Kim SK (2015) Recent update of autism spectrum disorders. Korean J Pediatr 58(1):8-14. https://doi.org/10.3345/kjp.2015.58.1.8

2. Seif Eldin A, Habib D, Noufal A, Farrag S, Bazaid K, Al-Sharbati M, Badr H, Moussa S, Essali A, Gaddour N (2008) Use of M-CHAT for a multinational screening of young children with autism in the Arab countries. Int Rev Psychiatry (Abingdon, England) 20(3):281-289. https://doi.org/10.1080/ 09540260801990324

3. Baio J, Wiggins L, Christensen DL, Maenner MJ, Daniels J, Warren Z, KurziusSpencer M, Zahorodny W, Robinson Rosenberg C, White T, Durkin MS, Imm P, Nikolaou L, Yeargin-Allsopp M, Lee LC, Harrington R, Lopez M, Fitzgerald RT, Hewitt A, Pettygrove $S$ et al (2018) Prevalence of autism spectrum disorder among children aged 8 years - Autism and Developmental Disabilities Monitoring Network, 11 Sites, United States, 2014. MMWR Surveill Summ (Washington, DC: 2002) 67(6):1-23 https://doi.org/10.15585/ mmwr.ss6706a1

4. Kerub O, Haas E, Menashe I, Davidovitch N, Meiri G (2018) Autism spectrum disorder: evolution of disorder definition, risk factors and demographic characteristics in Israel. Israel Med Assoc J 20(9):576-581

5. APA (1980) Diagnostic and statistical manual of mental disorders (3rd Edition) (DSM-III). American Psychiatric Association, Washington, DC
6. APA (1987) Diagnostic and Statistical Manual of Mental Disorders (3rd ed., rev. ed.). American Psychiatric Association, Washington, DC

7. APA (1994) Diagnostic and Statistical Manual of Mental Disorders, $4^{\text {th }}$ Edition American Psychiatric Association, Washington, DC

8. Howe FE, Stagg SD (2016) How sensory experiences affect adolescents with an autistic spectrum condition within the classroom. J Autism Dev Disord 46(5):1656-1668. https://doi.org/10.1007/s10803-015-2693-1

9. Germani T, Zwaigenbaum L, Bryson S, Brian J, Smith I, Roberts W, Szatmari P, Roncadin C, Sacrey LA, Garon N, Vaillancourt T (2014) Brief report: assessment of early sensory processing in infants at high-risk of autism spectrum disorder. J Autism Dev Disord 44(12):3264-3270. https://doi.org/ 10.1007/s10803-014-2175-x

10. APA (2013) Diagnostic and Statistical Manual of Mental Disorders, 5th edn. American Psychiatric Association, Washington, DC

11. Rutter M, Le CA, Lord C (2003) Autism diagnostic interview-revised (ADI-R). Western Psychological Services, Los Angeles

12. Dunn W (1999) The sensory profile: Examiner's manual. The Psychological Corporation, San Antonio

13. Schopler E, Reichler RJ, Renner BR (1988) The Childhood Autism Rating Scale. Western Psychological Services, Los Angeles

14. Kojovic N, Ben Hadid L, Franchini M, Schaer M (2019) Sensory processing issues and their association with social difficulties in children with autism spectrum disorders. J Clin Med 8(10):1508. https://doi.org/10.3390/jcm8101508

15. Posar A, Visconti $P$ (2018) Sensory abnormalities in children with autism spectrum disorder. J Pediatr 94(4):342-350. https://doi.org/10.1016/j.jped. 2017.08.008

16. Kitchin J (2016) Sensory Processing Specificity in Autism. Ursidae: Undergrad Res J Univ North Colorado 5(3):4

17. Brandwein AB, Foxe JJ, Butler JS, Russo NN, Altschuler TS, Gomes H, Molholm S (2013) The development of multisensory integration in highfunctioning autism: high-density electrical mapping and psychophysical measures reveal impairments in the processing of audiovisual inputs. Cerebral Cortex (New York, NY : 1991) 23(6):1329-1341

18. Thye MD, Bednarz HM, Herringshaw AJ, Sartin EB, Kana RK (2018) The impact of atypical sensory processing on social impairments in autism spectrum disorder. Dev Cogn Neurosci 29:151-167. https://doi.org/10.1016/j. dcn.2017.04.010

19. Hornix BE, Havekes R, Kas M (2019) Multisensory cortical processing and dysfunction across the neuropsychiatric spectrum. Neurosci Biobehav Rev 97:138-151

20. Hilton $\mathrm{CL}$, Harper JD, Kueker RH, Lang AR, Abbacchi AM, Todorov A, LaVesser PD (2010) Sensory responsiveness as a predictor of social severity in children with high functioning autism spectrum disorders. J Autism Dev Disord 40(8):937-945

21. Foss-Feig JH, Heacock JL, Cascio CJ (2012) Tactile responsiveness patterns and their association with core features in autism spectrum disorders. Res Autism Spectr Disord 6(1):337-344

22. Cascio CJ, Lorenzi J, Baranek GT (2016) Self-reported pleasantness ratings and examiner-coded defensiveness in response to touch in children with ASD: effects of stimulus material and bodily location. J Autism Dev Disord 46(5):1528-1537

23. Balasco L, Provenzano G, Bozzi Y (2020) Sensory abnormalities in autism spectrum disorders: a focus on the tactile domain, from genetic mouse models to the clinic. Front Psychiatry 10:1016

24. Tomchek S, Huebner R, Dunn W (2014) Patterns of sensory processing in children with an autism spectrum disorder. Res Autism Spectr Disord 8: 1214-1224

25. Caminha RC, Lampreia C (2012) Findings on sensory deficits in autism: implications for understanding the disorder. Psychol Neurosci 5(2):231-237. https://doi.org/10.1590/S1983-32882012000200014

26. Hannant P, Cassidy S, Tavassoli T, Mann F (2016) Sensorimotor difficulties are associated with the severity of autism spectrum conditions. Front Integr Neurosci 10:28

27. Lidstone J, Uljarevic M, Sullivan J, Rodgers J, McConachie H, Freeston M, Couteur A, Prior M, Leekam S (2014) Relations among restricted and repetitive behaviors, anxiety and sensory features in children with autism spectrum disorders. Res Autism Spectr Disord 8:82-92

28. Wigham S, Rodgers J, South M, McConachie H, Freeston M (2015) The interplay between sensory processing abnormalities, intolerance of uncertainty, anxiety and restricted and repetitive behaviours in autism spectrum disorder. J Autism Dev Disord 45(4):943-952 
29. Boyd BA, Baranek GT, Sideris J, Poe MD, Watson LR, Patten E, Miller H (2010) Sensory features and repetitive behaviors in children with autism and developmental delays. Autism Res 3(2):78-87

30. Black KR, Stevenson RA, Segers M, Ncube BL, Sun SZ, Philipp-Muller A, Bebko JM, Barense MD, Ferber S (2017) Linking anxiety and insistence on sameness in autistic children: the role of sensory hypersensitivity. J Autism Dev Disord 47(8):2459-2470

31. Gal E, Dyck M, Passmore A (2002) Sensory differences and stereotyped movements in children with autism. Behav Chang 19(4):207-219. https:// doi.org/10.1375/bech.19.4.207

32. Dellapiazza F, Vernhet C, Blanc N, Miot S, Schmidt R, Baghdadli A (2018) Links between sensory processing, adaptive behaviours, and attention in children with autism spectrum disorder: a systematic review. Psychiatry Res 270:78-88. https://doi.org/10.1016/j.psychres.2018.09.023

33. Tavassoli T, Miller $\amalg$, Schoen SA, Jo Brout J, Sullivan J, Baron-Cohen S (2018) Sensory reactivity, empathizing and systemizing in autism spectrum conditions and sensory processing disorder. Dev Cogn Neurosci 29:72-77. https://doi.org/10.1016/j.dcn.2017.05.005

34. Ben-Sasson A, Hen L, Fluss R, Cermak SA, Engel-Yeger B, Gal E (2009) A meta-analysis of sensory modulation symptoms in individuals with autism spectrum disorders. J Autism Dev Disord 39(1):1-11

35. Ausderau K, Sideris J, Furlong M, Little LM, Bulluck J, Baranek GT (2014) National survey of sensory features in children with ASD: factor structure of the sensory experience questionnaire (3.0). J Autism Dev Disord 44(4):915925

36. Tavassoli T, Bellesheim K, Siper PM, Wang AT, Halpern D, Gorenstein M, Grodberg D, Kolevzon A, Buxbaum JD (2016) Measuring sensory reactivity in autism spectrum disorder: application and simplification of a clinicianadministered sensory observation scale. J Autism Dev Disord 46(1):287-293

37. Green D, Chandler S, Charman T, Simonoff E, Baird G (2016) Brief report: DSM-5 sensory behaviours in children with and without an autism spectrum disorder. J Autism Dev Disord 46(11):3597-3606

38. Elwin M, Ek L, Kjellin L, Schröder A (2013) Too much or too little: hyper- and hypo-reactivity in high-functioning autism spectrum conditions. J Intellect Develop Disabil 38(3):232-241

39. Alshaban F, Aldosari M, Al-Shammari H, El-Hag S, Ghazal I, Tolefat M, Ali M Kamal M, Abdel Aati N, Abeidah M, Saad AH, Dekair L, Al Khasawneh M, Ramsay K, Fombonne E (2019) Prevalence and correlates of autism spectrum disorder in Qatar: a national study. J Child Psychol Psychiatry Allied Discip 60(12):1254-1268. https://doi.org/10.1111/jcpp.13066

40. Elbahaaey W, Elkholy M, Tobar S, El-Boraie H (2016) Egyptian children with autism spectrum disorders: risk factors and comorbidity in relation to disease severity. Egypt J Psychiatry 37(2):59

41. Mahajnah M, Sharkia R, Shalabe H, Terkel-Dawer R, Akawi A, Zelnik N (2015) Clinical characteristics of autism spectrum disorder in Israel: impact of ethnic and social diversities. Biomed Res Int 2015(1-7). https://doi.org/10. 1155/2015/962093

42. Sasanfar R, Haddad SA, Tolouei A, Ghadami M, Yu D, Santangelo SL (2010) Paternal age increases the risk for autism in an Iranian population sample. Mol Autism 1(1):2. https://doi.org/10.1186/2040-2392-1-2

\section{Publisher's Note}

Springer Nature remains neutral with regard to jurisdictional claims in published maps and institutional affiliations.

\section{Submit your manuscript to a SpringerOpen ${ }^{\circ}$ journal and benefit from:}

- Convenient online submission

- Rigorous peer review

- Open access: articles freely available online

- High visibility within the field

- Retaining the copyright to your article

Submit your next manuscript at $\boldsymbol{\nabla}$ springeropen.com 